\title{
Adsorption-desorption of oxytetracycline on marine sediments: Kinetics and influencing factors
}

\author{
Jia Li ${ }^{\text {a, b }}$, Hua Zhang ${ }^{\text {a, * }}$ \\ ${ }^{a}$ Key Laboratory of Coastal Environmental Process and Ecology Remediation, Yantai Institute of Coastal Zone Research, Chinese Academy of Sciences, Yantai \\ 264003, China \\ ${ }^{\mathrm{b}}$ University of Chinese Academy of Sciences, Beijing, China
}

\section{H I G H L I G H T S}

- OTC sorption on marine sediments were investigated using batch and stirred flow chamber (SFC) experiments.

- Second order kinetic model successfully described OTC adsorption/desorption kinetics.

- Adsorption/desorption rate is controlled by diffusive mass transfer process.

- Solution pH and salinity have large impact on the extent of OTC sorption.

- A weak hysteresis was observed in OTC adsorption-desorption process.

\section{A R T I C L E I N F O}

\section{Article history:}

Received 31 March 2016

Received in revised form

15 August 2016

Accepted 21 August 2016

\section{Handling Editor: Keith Maruya}

\section{Keywords:}

Oxytetracycline

Adsorption

Desorption

Kinetics

Influencing factors

Stirred flow chamber

\begin{abstract}
A B S T R A C T
To reveal the kinetics and mechanisms of antibiotic adsorption/desorption processes, batch and stirred flow chamber (SFC) experiments were carried out with oxytetracycline (OTC) on two marine sediments. The OTC adsorption capacities of the marine sediments were relatively weak and related to their organic carbon (OC) and contents of fine particles. Sorption isotherms of OTC on marine sediment can be well described by both the Langmuir and Freundlich models. Langmuir adsorption maxima $\left(q_{\max }\right)$ and Freundlich distribution coefficients $\left(K_{f}\right)$ increased with the decrease of salinity and $\mathrm{pH}$, which indicated the importance of variable charged sites on sediment surfaces. A second order kinetic model successfully described adsorption and desorption kinetics of OTC and well reproduced the concentration change during stop-flow. The adsorption kinetic rates $\left(k_{a}\right)$ for OTC under different experimental conditions ranged from $2.00 \times 10^{-4}$ to $1.97 \times 10^{-3} \mathrm{~L}(\mathrm{mg} \mathrm{min})^{-1}$. Results of SFC experiments indicated that diffusive mass transfer was the dominant mechanism of the time-dependent adsorption of OTC and its release from marine sediment was mildly hysteretic. The high desorption percentage (43-75\% for LZB and 58 $-75 \%$ for BHB) implied that binding strength of OTC on two marine sediments was weak. In conclusion, marine sediment characteristics and environmental factors such as salinity, $\mathrm{pH}$, and flow rate are critical factors determine extent of OTC sorption on marine sediment and need to be incorporated in modeling fate and transport of OTC in marine environment.
\end{abstract}

() 2016 Elsevier Ltd. All rights reserved.

\section{Introduction}

Tetracyclines (TCs), the second most widely used antibiotics, are mainly used in the livestock industry and aquaculture (Jones et al., 2002). Statistics showed that the total usage of TCs is $9.7 \times 10^{4}$ tons in China, accounting for $46 \%$ of the total antibiotics (Liu and Bao,

\footnotetext{
* Corresponding author.

E-mail address: hzhang@yic.ac.cn (H. Zhang).
}

2011). Earlier study showed that about $70-90 \%$ of TCs were released in excreta and entered into the receiving environment following various wastewater treatments (Jjemba, 2002). Presence of these antibiotics in the environment has become a research focus because the induction and spread of antibiotic resistance genes (Zhang and Zhang, 2011).

Aquaculture is an important economy sector in coastal region, where antibiotics (e.g. oxytetracycline, ormetoprim, and sulfadiazine) are routinely used to treat infectious diseases (Heuer et al., 2009). Antibiotic residues have been found in coastal water, 
sediment, and wild organisms in aquaculture areas (Chelossi et al., 2003; Le and Munekage, 2004). Furthermore, the tetracyclineresistance gene was detected in marine sediments (Nonaka et al., 2007) and it can persist for several years in aquaculture area (Tamminen et al., 2011). Antibiotic residues may influence coastal or marine environments and human health if released into the environment (Zhang et al., 2011). Therefore, there is an urgent need to understand the fate and transport of antibiotics in marine environment.

It is well established that sorption process is a key determinant of the migration and transformation of organic pollutants in natural waters. Understanding mechanisms of adsorption and desorption of TCs is necessary to predict their fate and behavior in aquatic environment. Oxytetracycline (OTC), the earliest and the most widely used TCs, is an amphoteric molecule with several ionic/polar groups (Jones et al., 2005). The possible mechanisms of OTC adsorption onto sediments include the ion exchange, electrostatic forces, and surface complexation reactions (Jones et al., 2005). Carrasquillo et al. (2008) suggested that the adjacent hydroxyl groups on OTC molecule facilitated a greater potential for surface complexation to soil metal oxides. Additionally, Song et al. (2014) reported that the main adsorption mechanism of OTC to activated sludge was surface complexation through metal bridging and cation $-\pi$ interactions. Studies have revealed that absorbent structure and environmental factors such as $\mathrm{pH}$, ionic strength and temperature can influence the adsorption/desorption process of OTC significantly (Jones et al., 2005; ter Laak et al., 2006; Xu and Li, 2010). However, most studies were carried out using 24 or 48 h equilibrium batch experiments, which are unable to reveal the kinetics and mechanisms of adsorption/desorption processes. Recently, Fernandez-Calvino et al. (2015) used the stirred flow chamber (SFC) technique to study retention and release of TCs on acidic soils and found that a strong hysteresis existed in the adsorption/desorption processes.

The objective of this study were (1) to determine the extent of OTC sorption on marine sediments with different properties with equilibrium batch experiment, (2) to investigate the influence of $\mathrm{pH}$, salinity, flow rate, and organic carbon (OC) content on timedependent adsorption/desorption of OTC using SFC technique, and (3) to evaluate the capability of second order kinetic model for describing the sorption process of OTC under different conditions.

\section{Materials and methods}

\subsection{Chemicals}

Pure oxytetracycline was purchased from Sigma (USA) and was of analytical grade. The physicochemical properties of OTC are shown in Table S1. The other reagents and solvents were of analytical reagent grade or better. Ultrapure water (MQ) was obtained from a Milli-Q water purification system (Millipore, Billerica, MA, USA). OTC was dissolved in methanol to prepare the stock solution. Working solutions were prepared by diluting stock solution using seawater collected from Bohai Sea. Before use, seawater was filtered through $0.45 \mu \mathrm{m}$ membranes and irradiated with ultraviolet light. The salinity of the seawater was $34 \%$ and the $\mathrm{pH}$ value was 8.1 .

\subsection{Marine sediment samples and physicochemical analysis}

In August 2014, two surface sediment samples were collected from Bohai Bay (BHB) and Laizhou Bay (LZB). The sediment samples were freeze-dried. After removing the shells and gravels, sediment samples were ground into particles and then pass through a 60mesh sieve. The particle size distribution of sediment samples were measured using a laser particle size analyzer (Marlvern Mastersizer 2000F, Malvern, UK). The point of zero charge (PZC) of marine sediment was analyzed based on the method described by FerroGarcia et al. (1998). The sediment microscopic morphological characteristics and element composition on the surface of the sediment were analyzed by a Scanning Electron Microscope-Energy Dispersive Spectrometer (SEM-EDS) (S-4800, Hitachi, Japan). Total organic carbon (TOC) content of sediment samples was determined on dried sediment by dry combustion using an elemental analyzer (Vario MACRO cube, Elementar, Germany). Additionally, a fraction of each sediment sample was further treated with $\mathrm{H}_{2} \mathrm{O}_{2}$ to remove OC using the method of Xu and Li (2010).

\subsection{Batch-type sorption experiments}

Sorption isotherms of OTC were determined using equilibrium batch experiments. To initiate the experiments, a $30 \mathrm{~mL}$ glass vial equipped with screw cap received $0.02 \mathrm{~g}$ sediment, followed by stock solution of OTC. The treated seawater with sodium azide at $0.02 \%$ (by weight) was then added to make up the suspension volume of $10 \mathrm{~mL}$ in each glass vial. Final concentrations of OTC in the mixture were $0.5,1,5,10,15 \mathrm{mg} \mathrm{L}^{-1}$. The glass vials was shaken at $25{ }^{\circ} \mathrm{C}$ in a temperature-controlled shaking incubator (Harbin, China) at a shaking speed of $190 \mathrm{rpm}$. The shaking incubator was covered with black cloth aim to prevent the occurrence of photodegradation. After $24 \mathrm{~h}$, the glass vial was centrifuged at $4000 \mathrm{rpm}$ for $10 \mathrm{~min}$, then the supernatant was filtered through a $0.22 \mu \mathrm{m}$ syringe filter before analysis. Two blank sorption experiments, one with the reactor system containing OTC without sediment and another containing sediment without OTC, were carried out. The loss of OTC during sorption test was less than $5 \%$ and that no pollution of OTC was introduced by the marine sediment. All adsorption studies were conducted in triplicate.

\subsection{Kinetic adsorption/desorption experiments}

SFC reactor was used to conduct the adsorption and desorption kinetics experiment. Detail information about the experimental equipment was shown in S1 and Fig. S1. A $1.0 \mathrm{~g}$ sample of marine sediment was placed in the reactor with a magnetic stirring bar. Working solution with an OTC concentration of $1.5 \mathrm{mg} \mathrm{L}^{-1}$ was pumped into the reactor using peristaltic pump. A fraction collector (BS-100A, China) was used to collect effluent sample at 5 min interval. A stopped-flow test for 180 min was performed after 49 samples were collected. Once 80 samples were collected, the working solution was emptied and replaced by background solution (treated seawater) to carry out the desorption experiment in accordant with the kinetic sorption test.

\subsection{Effects of environmental factors}

The influences of environmental factors such as solution $\mathrm{pH}$, salinity, flow rate and sediment $\mathrm{OC}$ content were investigated using batch-type or SFC experiments. For the $\mathrm{pH}$ effect, $\mathrm{pH}$ values of reaction system were adjusted to 6.9 or 7.5 using sulfuric acid from the initial $\mathrm{pH}(=8.1)$. For the salinity study, seawater was diluted using ultrapure water into solutions with salinity value of $17 \%$, $22 \%$, and $34 \%$, respectively. All salinity experiments were studied with $\mathrm{pH}$ at 8.0-8.1. Kinetic adsorption/desorption test was conducted using SFC experiments in two flow rates (0.56 and $0.82 \mathrm{~mL} \mathrm{~min}^{-1}$ ) to assess the impact of different flow rate on OTC adsorption/desorption. To explore the effect of OC content, batchtype and SFC experiments were carried out on the raw and $\mathrm{H}_{2} \mathrm{O}_{2}-$ treated sediments under same experiment condition $(\mathrm{pH}=8.1$ and Salinity $=34 \% 0$ ). 


\subsection{Detection of OTC}

OTC in solution was detected using ultra-performance liquid chromatography (UPLC) equipped with a photo-diode array detector set at $268 \mathrm{~nm}$, a $2.1 \times 5 \mathrm{~mm}$ VanGuard pre-column, and an ACQUITY UPLC BEH C18 column $(2.1 \times 50 \mathrm{~mm}, 1.7 \mu \mathrm{m}$ particles $)$. The column temperature was $25^{\circ} \mathrm{C}$. Injection volume was $2 \mu \mathrm{L}$ for adsorption samples and $10 \mu \mathrm{L}$ for desorption samples. Mobile phase A was acetonitrile and B was ultrapure water with $0.4 \%$ acetic acid (30:70, v/v). The detection limit of this method was $10 \mu \mathrm{g} \mathrm{L}^{-1}$ with blank seawater as background according to our pretests.

\subsection{Second order kinetic model}

The adsorption-desorption of OTC is described by the second order kinetic model based on the Langmuir sorption mechanism (Ma and Selim, 1994; Zhang and Selim, 2011). The model can be described in the following equations:

$\frac{\partial q}{\partial t}=k_{a}\left(q_{\max }-q\right) C-k_{d} q$

Where $q\left(\mathrm{mg} \mathrm{g}^{-1}\right)$ is amount of OTC sorbed on sediment, $q_{\max }$ is maximum sorption amount, $C\left(\mathrm{mg} \mathrm{L}^{-1}\right)$ is the solution concentration of OTC, $k_{a}\left(\mathrm{~L}(\mathrm{mg} \mathrm{min})^{-1}\right)$ and $k_{d}\left(\mathrm{~min}^{-1}\right)$ are adsorption and desorption rate coefficient, respectively. Under equilibrium condition $\left(\frac{\partial q}{\partial t}=0\right)$, equation (1) is equivalent to the Langmuir equation

$q=q_{\max } \frac{K_{L} C}{1+K_{L} C}$

Where $K_{L}=\frac{k_{a}}{k_{d}}\left(\mathrm{~L} \mathrm{mg}^{-1}\right)$ is the Langmuir adsorption coefficient that can be related to binding strength.

The transport of OTC in flowing chamber can be described using the one dimensional steady-state reaction-advection equation with the following formulations:

$V \frac{\partial C}{\partial t}+m \frac{\partial q}{\partial t}=Q\left(C_{0}-C\right)$

Where $V\left(\mathrm{~cm}^{3}\right)$ represents the reaction volume of the reactor, $m(\mathrm{~g})$ is the mass of marine sediment, $Q\left(\mathrm{~mL} \mathrm{~min}^{-1}\right)$ is the flow rate. $C_{0}$ is the input concentration of OTC $\left(\mathrm{mg} \mathrm{L}^{-1}\right)$. Given kinetic parameters $\left(q_{\max }, k_{a}\right.$, and $\left.k_{d}\right)$ and column settings $(V, m, Q)$, the second order model can be used to calculate the time-dependent evolution of aqueous concentration $(C)$ and amount of sorption $(q)$ under various initial conditions. Numerical solution of Eqs. (1) and (3) was achieved using the classical fourth-order Runge-Kutta (RK) method (Press et al., 1992).

The adsorption and desorption kinetic rate coefficients $\left(k_{a}\right.$ and $k_{d}$ ) and the maximum sorption amount, $q_{\max }$, need to be determined from the kinetic experiment data. The Levenberg-Marquardt nonlinear least square optimization method was employed to iteratively fitting model parameters to experiment results (Press et al., 1992). Statistical criteria used for estimating the goodnessof-fit of the models to the data were the coefficients of determination $\left(R^{2}\right)$ and the root mean square error (RMSE):

$R M S E=\sqrt{\frac{\sum\left(C_{o b s}-C_{m o d}\right)^{2}}{n_{o b s}-n_{p a r}}}$

Where $C_{o b s}$ is the observed OTC concentration at certain time t, $C_{\text {mod }}$ is the simulated OTC concentration at time $t, n_{o b s}$ is the number of measurements, and $n_{p a r}$ is the number of fitted parameters.

\section{Results and discussion}

\subsection{Sediment characteristics}

The basic properties of two kinds of marine sediments are given in Table 1. Both the marine sediments were alkaline and the $\mathrm{pH}_{\mathrm{pzc}}$ values were 9.2 and 9.4 for sediment BHB and LZB, respectively. Since $\mathrm{pH}$ of sorption experiments was less than the $\mathrm{pH}_{\mathrm{pzc}}$ values, sediment surface carries a small amount of positive charge. The total organic carbon (TOC) contents in sediment BHB and LZB were $0.48 \%$ and $0.15 \%$, respectively. SEM results showed that the particle size of sediment BHB was smaller than that of sediment LZB (Fig. S2), which was consistent with results from laser particle size analyzer (Table 1). The fine particles (silt and clay) fraction in sediment BHB and LZB were $99.5 \%$ and $52.8 \%$, respectively. The contents of $\mathrm{Al}\left(\mathrm{as}_{2} \mathrm{Al}_{3}\right)$ on the surface of sediment BHB and LZB were $7.21 \%$ and $2.78 \%$, respectively. The contents of Fe were $3.94 \%$ and $0.93 \%$ for BHB and LZB, respectively.

\subsection{Sorption isotherms}

Equilibrium sorption isotherms are showed in Fig. 1 and their Linear model $q=K_{d} C$ ( $K_{d}$ is distribution coefficient), Langmuir model (Eq. (2)), and Freundlich model $q=K_{F} C^{n}\left(K_{F}\right.$ is the Freundlich distribution coefficient and $n$ is a nonlinear coefficient) parameters are summarized in Table S2, S3, and S4. Both Langmuir and Freundlich equations are suitable to fit the OTC sorption isotherms, as shown by high $\mathrm{R}^{2}$ values (0.988 and 0.999 ), which is consistent with previous studies about OTC adsorption on soils (Rabolle and Spliid, 2000; Jones et al., 2005). The nonlinear sorption behavior of OTC on marine sediment is exhibited by Freundlich $n$ ranged from 0.627 to 0.922 , which are similar to the values reported by Xu and Li (2010). Values of $n$ also indicate the extent of heterogeneity of the sorption sites. The $n$ values of LZB are slightly lower than those of $\mathrm{BHB}$, indicating higher degree of heterogeneity compared to BHB. As a relative indicator of sorption capacity, Freundlich coefficient $k_{f}$ increase with decrease of $\mathrm{pH}$ and salinity. Correspondingly, Langmuir sorption maxima $q_{\max }$ also demonstrates that OTC sorption decreases with increasing $\mathrm{pH}$ and salinity. This differential response of sorption quantity to changes in salinity and $\mathrm{pH}$ between the two sediments can be attributed to their different physicochemical properties.

Experiment results exhibited that adsorption capacity of sediment BHB is higher than that of sediment LZB. At $\mathrm{pH}$ of 8.1 and salinity of $34 \%$, adsorption capacity $\left(q_{\max }\right)$ of BHB $\left(5.03 \mathrm{mg} \mathrm{g}^{-1}\right)$ was an order of magnitude higher than that of LZB $\left(0.602 \mathrm{mg} \mathrm{g}^{-1}\right)$. This can be explained by the higher content of total organic material and fine particles in sediment BHB (Table 1) and agrees with previous studies, which showed that both fine particles and OC have high adsorption capacity for antibiotics (Maszkowska et al., 2013; Xu and Li, 2010). Overall, sorption quantity of OTC on two selected sediments are small due to their low TOC content.

\subsection{Effect of salinity on OTC adsorption}

The adsorption isotherms of Fig. 1a and b shows that sorption of OTC on two marine sediments decrease with an increase of salinity, which is consistent with previous reports on tetracycline adsorption on marine sediment (Wang et al., 2010; Xu and Li, 2010). As the salinity increased from $17 \%$ o to $34 \%$, $q_{\max }$ decreased substantially from 7.53 to $0.602 \mathrm{mg} \mathrm{g}^{-1}$ for LZB and from 10.9 to $5.03 \mathrm{mg} \mathrm{g}^{-1}$ for BHB (Table S2). In addition, adsorption became more nonlinear with increasing salinity as demonstrated by decreasing Freundlich $n$ values. Several possible mechanisms might be responsible for salinity or ion strength effect on antibiotics adsorption. Presence of 
Table 1

Basic physicochemical properties of marine sediments.

\begin{tabular}{|c|c|c|c|c|c|c|c|}
\hline \multirow[t]{2}{*}{ Sediment } & \multirow[t]{2}{*}{ TOC (\%) } & \multirow[t]{2}{*}{$\mathrm{Al}^{\mathrm{a}}(\%)$} & \multirow[t]{2}{*}{$\mathrm{Fe}^{\mathrm{b}}(\%)$} & \multicolumn{3}{|c|}{ Particle size distribution (\%) } & \multirow[t]{2}{*}{$\mathrm{pH}_{\mathrm{zpc}}$} \\
\hline & & & & Sand $(>60 \mu \mathrm{m})$ & Silt $(4-60 \mu \mathrm{m})$ & Clay $(<4 \mu \mathrm{m})$ & \\
\hline LZB & 0.15 & 2.78 & 0.93 & 47.2 & 44.3 & 8.50 & 9.4 \\
\hline BHB & 0.48 & 7.21 & 3.94 & 0.50 & 68.8 & 30.7 & 9.2 \\
\hline
\end{tabular}

$\mathrm{a}, \mathrm{b}$ : Elemental (weight percentage wt\%) on the surface of the sediment analyzed by SEM-EDS.

anions such as $\mathrm{Cl}^{-}$and $\mathrm{SO}_{4}^{2-}$ may influence the sorption process of deprotonated OTC through ion exchange. Abundant cations may substitute the $\mathrm{H}^{+}$of the acidic groups (e.g. $\mathrm{COOH}$ and $\mathrm{OH}$ ) in organic matter and reduce effective hydrophobic surface area (Wershaw, 1986). Yang et al. (2011) reported that H-bonding was an important interaction in OTC adsorption process because OTC contained several groups capable of $\mathrm{H}$-bonding as $\mathrm{H}$ acceptor (e.g. amide carbonyl and hydroxyl). The amide carbonyl group can also bind $\mathrm{Na}^{+}$(Aristilde et al., 2010). Therefore, presence of $\mathrm{Na}^{+}$will inhibit the formation of H-binding. Furthermore, hydrophobic interaction between tetracycline molecules may overpower the electrostatic repulsion under high ionic strengths condition and cause aggregation of tetracycline (Turku et al., 2007), which results in lower adsorption at high salinity level since large aggregates are difficult to reach the sorption sites in sediment pores.

\subsection{Effect of $\mathrm{pH}$ on OTC adsorption}

Solution pH can affect the speciation of OTC molecule, in addition to its effect on specific and nonspecific binding sites on sediment surfaces. OTC is an amphoteric molecule with several ionic/ polar groups such as the tertiary amine functionality and the

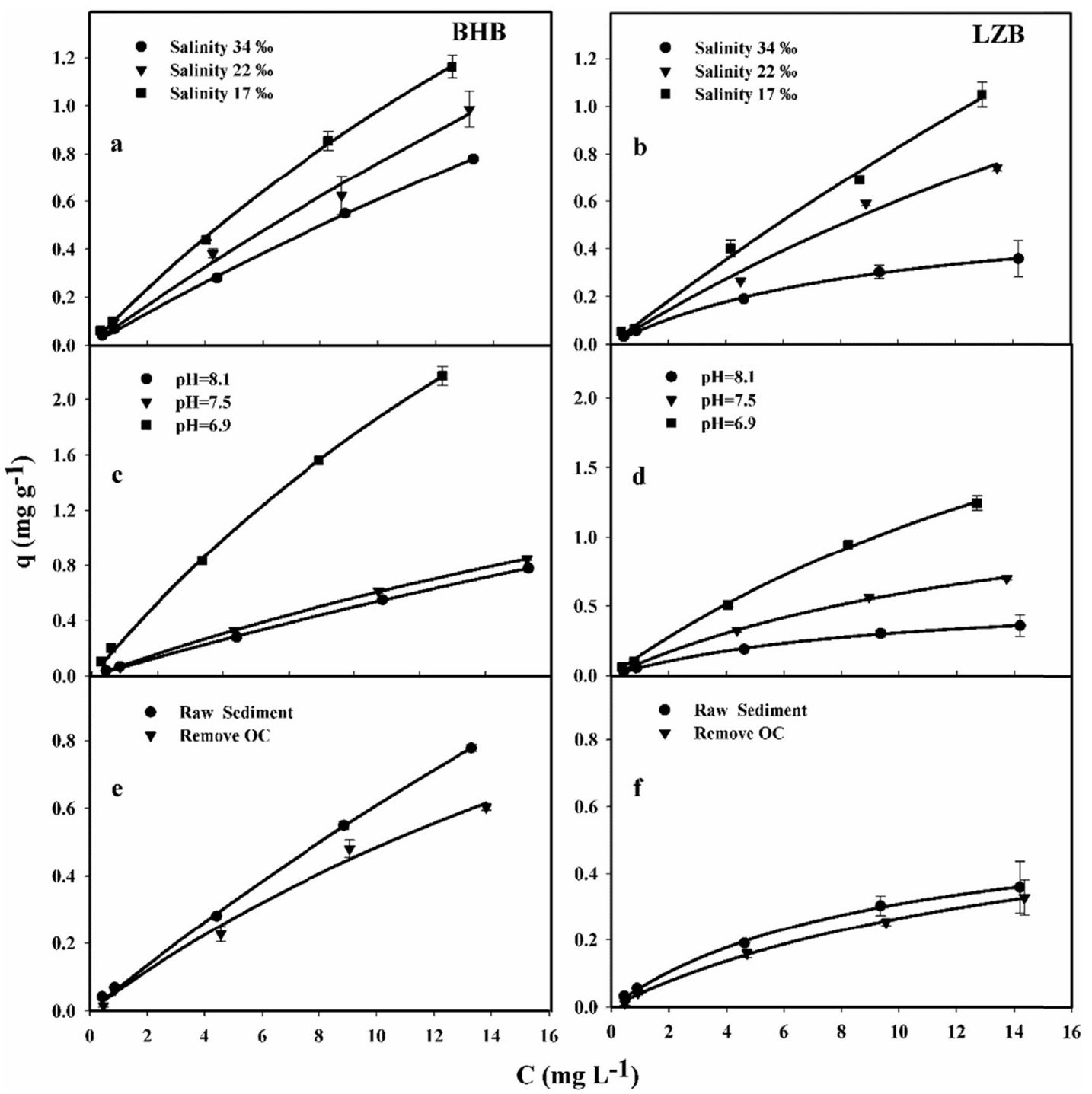

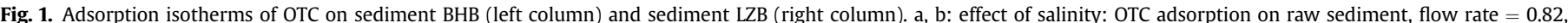

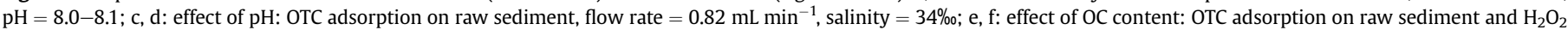
treated sediment, flow rate $=0.82 \mathrm{~mL} \mathrm{~min}^{-1}$, salinity $=34 \%, \mathrm{pH}=8.1$. Solid curves are simulation with Langmuir equation. 
hydroxyl group (Jones et al., 2005). At pH of 6.9, neutral zwitterions (ionization is +-0 ) is the dominate species, accounting for $70 \%$ of the total OTC molecules; at pH of 7.5, percentage of OTC molecules with a net negative charge (ionization is +-- ) is about $40 \%$, while percentage of neutral zwitterions reduce to $60 \%$; when $\mathrm{pH}$ increase to 8.1 , the percentage of negative ion increase to $80 \%$ (Jones et al., 2005). As seawater pH value increases, the mass fraction of the deprotonated (anionic) form of OTC increases accordingly and the non-ionized OTC decreases. The surface charge of marine sediment is determined by its PZC (Hendershot et al., 1979). The range of $\mathrm{pH}$ (6.9-8.1) in sorption experiment is lower than the PZC of sediment BHB (9.2) and sediment LZB (9.4), thus both sediments carry a net positive charge and the amount of positive charge decrease with increasing solution $\mathrm{pH}$.

Sorption isotherms in Fig. 1c and d indicate a decrease in OTC sorption capacity when $\mathrm{pH}$ increase from 6.9 to 8.1, which is not surprising considering the electronic charge of OTC and sediment surface. Adsorption of OTC on sediment surface is dominated by the hydrophobic partitioning of non-ionized OTC on organic matter and electrostatic attraction of anionic OTC on positively charged sediment surfaces (Sassman and Lee, 2005). With increasing pH, hydrophobic partitioning decreases as more unionized OTC turn into anionic species due to deprotonation reaction. Meanwhile, decreasing positive charge on variable charged surface result in weakened electrostatic attraction of anions on sediment.

\subsection{Effect of sediment OC content on OTC adsorption}

The OC content of soil and sediment has a great influence on sorption behavior of organic pollutants (Drillia et al., 2005). As shown in Fig. 1e and $\mathrm{f}$, removal of organic matter results in reduction of OTC adsorption for both sediments but a large amount of OTC remain adsorbed to sediments treated with $\mathrm{H}_{2} \mathrm{O}_{2}$. This phenomenon could be ascribed to the low OC content of the selected marine sediments. It is expected that the organic matter may play a more important role for antibiotic adsorption in nearshore and/or deep sea sediments with higher OC contents. Cornelissen et al. (2006) reported that organic matter (OM) of sediments mainly consists of amorphous materials and condensed aromatic materials. The condensed materials are considered to exhibit nonlinear sorption behavior, slower rates of sorption, and possible sorption-desorption hysteresis. Conversely, the amorphous materials often exhibit linear sorption behavior, faster rates of sorption, and no sorption-desorption hysteresis (Huang et al., 1997). The amorphous organic matter covering the sediment surfaces is believed to be easily oxidized and removed by chemical oxidation such as $\mathrm{H}_{2} \mathrm{O}_{2}$, while the condensed materials cannot. Therefore, contact area between OTC molecule and adsorption sites of inorganic constituents in the sediment surface will increase, and the impact of micropores is also larger. However, the increase of micropores and adsorption sites of inorganic constituents cannot offset the decrease of OTC adsorption caused by removing of organic carbon. Study about TCs adsorption on soils also indicated that sorption of antibiotics to soil minerals is weaker than to soil organic matter (Thiele-Bruhn, 2003).

\subsection{Adsorption kinetics}

Using SFC technique, we studied the effects of flow rate, salinity, $\mathrm{pH}$, and sediment OC content on OTC adsorption and desorption kinetics. Adsorption results are presented in Fig. 2 in order to illustrate the changes in effluent OTC concentrations versus time for various experimental conditions. During adsorption process, the effluent OTC concentrations increased with time except during the flow interruption, which indicate the slow saturation of adsorption sites. The OTC concentrations decreased during stop-flow events, clearly exhibiting the time-dependent or non-equilibrium adsorption process. This result is in agreement with the TCs adsorption behavior observed on several acidic soils (Fernandez-Calvino et al., 2015).

As shown in Fig. 2, effects of salinity and OC on OTC adsorption kinetics are consistent with equilibrium adsorption experiments. In addition, $\mathrm{pH}$ can significantly influence the kinetics behavior of OTC adsorption as demonstrated by reduction of effluent OTC concentrations dramatically with the decrease of $\mathrm{pH}$, and the discussion and result were shown in S2 and Fig. S3. Higher flow rate resulted in lower adsorption of OTC on sediments, as demonstrated by the higher effluent OTC concentrations at higher flow rates during the adsorption process. When flow rate is $0.56 \mathrm{~mL} \mathrm{~min}^{-1}$, OTC adsorption approaches the sorption capacity of sediment BHB after about $280 \mathrm{~mL}$, whereas when flow rate is $0.82 \mathrm{~mL} \mathrm{~min}^{-1}$, effluent OTC concentration increases until $430 \mathrm{~mL}$. A similar trend is also found for sediment LZB. The effect of flow rate indicates that physical non-equilibrium, i.e., diffusive transport of solute to sorption sites, may be a contributing mechanism to sorption kinetics.

The second order kinetic model with two fitted parameters ( $q_{\max }$ and $k_{a}$ ) successfully reproduced the kinetic behavior of OTC adsorption for marine sediments under different experimental conditions (Fig. 2) and the optimized model parameters are summarized in Table 2. Although the $q_{\max }$ obtained from curve fitting change significantly under different experimental conditions, the adsorption rate $k_{a}$ show small variation (range from $2.00 \times 10^{-4}$ to $\left.1.97 \times 10^{-3} \mathrm{~L}(\mathrm{mg} \mathrm{min})^{-1}\right)$ among two sediments. This demonstrates that various experimental conditions set in our study influence a little to the kinetic rates.

Both kinetic reactions and diffusive mass transfer may be responsible for sorption-related nonequilibrium (Brusseau et al., 1991). Our experiment results indicate that diffusive mass transfer is the dominant mechanism of the time-dependent adsorption of OTC on marine sediments. The diffusive mass transfer might consist of film diffusion, intrapartical (pores) diffusion, and intrasorbent (matrix) diffusion (Brusseau et al., 1991). Although film diffusion was insignificant compared to intrapartical diffusion in well-mixed batch systems, Miller and Weber (1988) concluded that film diffusion was significant for nitrobenzene adsorption in columns. Intrapartical diffusion can occur in pore liquids or along pore wall surfaces. Several factors such as sorbent structure, particle size distribution, and diffusant structure can influence intrapartical diffusion kinetics. Brusseau and Rao (1991) reported that diffusion was difficult for sorbate molecule with complex functional groups. Adsorption kinetic rate of OTC was faster on sediment BHB than sediment LZB (Table 2). This was possibly due to the fact that particle size of sediment BHB was smaller than sediment LZB and pore path length was shorter, which facilitated sorbate reaching sorption sites. Chemical mechanisms such as formation of H-bonding might also contribute to the overall kinetic rate of OTC adsorption. Brusseau and Rao (1991) reported that the making of H-bonding will decrease adsorption rate. At high salinity, cations interrupt $\mathrm{H}$ bonding formation of OTC and increase adsorption rates, which is consist with our fitting result, that is, $k_{a}$ values increase with increase of salinity (Table 2).

\subsection{Desorption kinetics}

Kinetic desorption of adsorbed OTC were determined in SFC and the results are shown in Fig. 3. Effluent OTC concentration decrease gradually, except for the stop-flow process, and then remain stable. After stopping the flow, all the effluent OTC concentrations in different experimental conditions increase, indicating desorption 


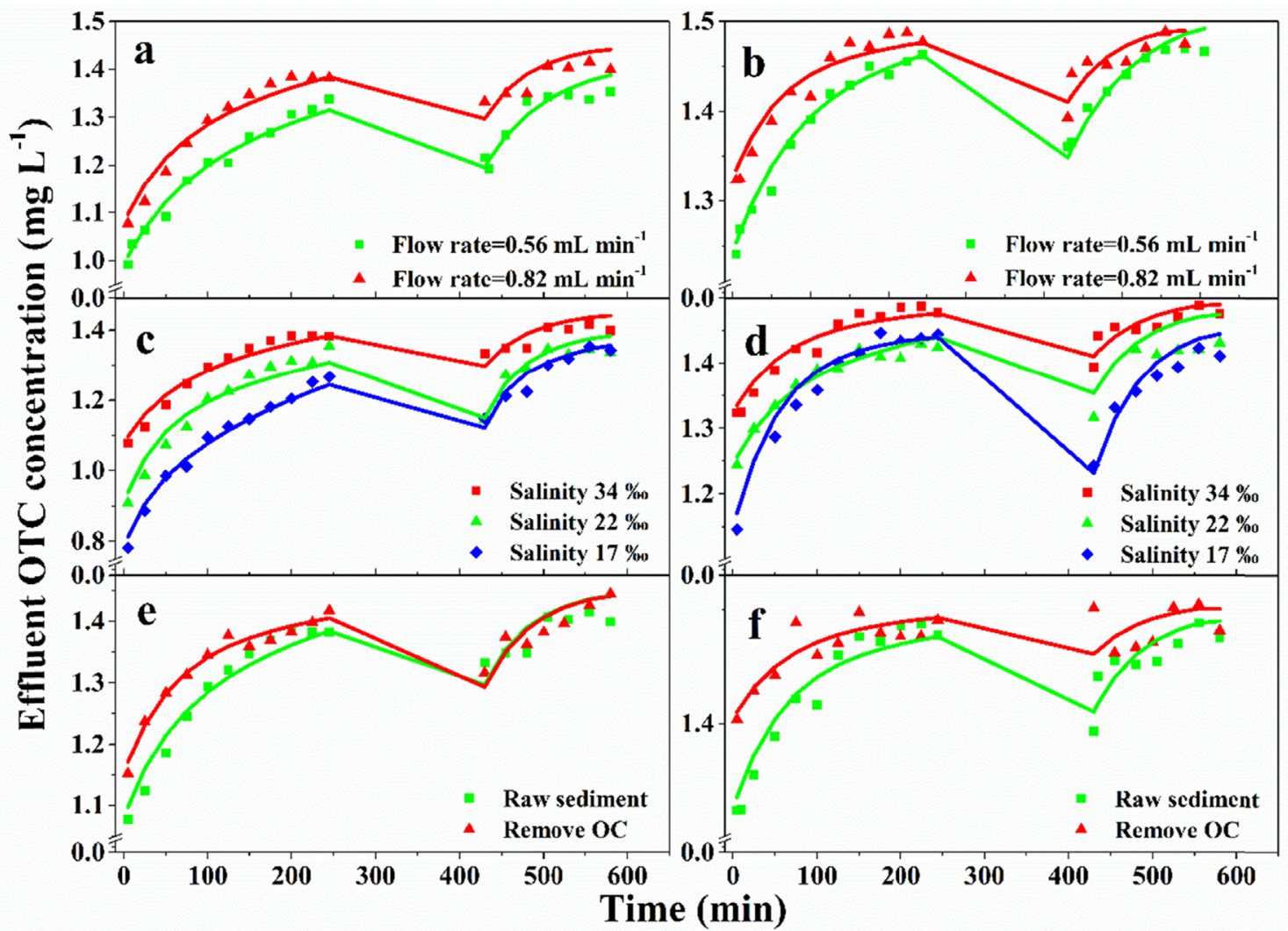

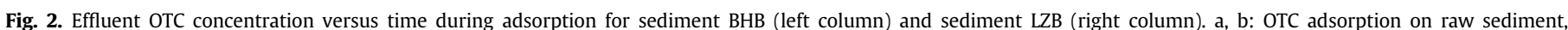

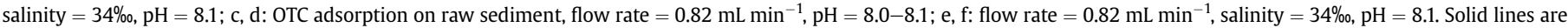
second order kinetic model simulations using parameters in Table 2.

Table 2

Optimized second order kinetic model parameters for adsorption of OTC on marine sediments.

\begin{tabular}{|c|c|c|c|c|c|c|c|}
\hline \multirow[t]{2}{*}{ Sediment } & \multirow{2}{*}{$\frac{\text { Flow rate }}{\mathrm{mL} \mathrm{min}^{-1}}$} & \multirow{2}{*}{$\frac{\text { Salinity }}{\% 0}$} & \multirow{2}{*}{$\frac{\text { Remove OC }}{\mathrm{Y} / \mathrm{N}}$} & \multirow{2}{*}{$\frac{q_{\max }}{\mathrm{mg} \mathrm{g}^{-1}}$} & \multirow{2}{*}{$\frac{k a}{\mathrm{~L}(\mathrm{mg} \mathrm{min})^{-1}}$} & \multirow[t]{2}{*}{$\mathrm{R}^{2}$} & \multirow[t]{2}{*}{ RMSE } \\
\hline & & & & & & & \\
\hline \multirow[t]{5}{*}{ BHB } & 0.56 & 34 & $\mathrm{~N}$ & $3.97 \pm 0.108$ & $1.24 \times 10^{-3} \pm 1.3 \times 10^{-4}$ & 1.00 & 0.0204 \\
\hline & 0.82 & 34 & $\mathrm{~N}$ & $3.26 \pm 0.141$ & $1.64 \times 10^{-3} \pm 2.4 \times 10^{-4}$ & 1.00 & 0.0250 \\
\hline & 0.82 & 34 & $\mathrm{Y}$ & $1.42 \pm 0.063$ & $1.97 \times 10^{-3} \pm 2.8 \times 10^{-4}$ & 1.00 & 0.0167 \\
\hline & 0.82 & 22 & $\mathrm{~N}$ & $6.85 \pm 0.314$ & $1.15 \times 10^{-3} \pm 1.6 \times 10^{-4}$ & 0.999 & 0.0317 \\
\hline & 0.82 & 17 & $\mathrm{~N}$ & $9.71 \pm 0.255$ & $1.50 \times 10^{-3} \pm 1.2 \times 10^{-4}$ & 1.00 & 0.0217 \\
\hline \multirow[t]{5}{*}{ LZB } & 0.56 & 34 & $\mathrm{~N}$ & $0.814 \pm 0.048$ & $1.79 \times 10^{-3} \pm 2.9 \times 10^{-4}$ & 1.00 & 0.0118 \\
\hline & 0.82 & 34 & $\mathrm{~N}$ & $0.718 \pm 0.063$ & $1.51 \times 10^{-3} \pm 4.6 \times 10^{-4}$ & 1.00 & 0.0157 \\
\hline & 0.82 & 34 & $\mathrm{Y}$ & $0.623 \pm 0.081$ & $1.32 \times 10^{-3} \pm 7.4 \times 10^{-4}$ & 1.00 & 0.0170 \\
\hline & 0.82 & 22 & $\mathrm{~N}$ & $1.65 \pm 0.124$ & $1.06 \times 10^{-3} \pm 2.0 \times 10^{-4}$ & 1.00 & 0.0152 \\
\hline & 0.82 & 17 & $\mathrm{~N}$ & $8.21 \pm 2.47$ & $2.00 \times 10^{-4} \pm 9.0 \times 10^{-4}$ & 1.00 & 0.0204 \\
\hline
\end{tabular}

of OTC is also time-dependent or non-equilibrium. Desorption curves demonstrate that at certain experimental conditions, that is, high flow rate, high salinity and removing OC, effluent OTC concentrations are relatively low. In contrast, at low flow rate and low salinity, as the amounts of adsorbed increased, the percentage of desorption for both two marine sediments increased. This phenomenon implied that more adsorption result in high percentage of desorption, which is consistent with the study reported by Xu and $\mathrm{Li}$ (2010). Overall, the total amount of OTC released, as a percentage of that adsorbed, were $43-75 \%$ and $58-75 \%$ for sediment LZB and sediment BHB, respectively. The high desorption observed in our study implied that binding force of OTC on two selected marine sediments is relatively weak.

After extensive desorption, a fraction of OTC remain adsorbed on sediment, indicating adsorption/desorption hysteresis. The observed hysteresis was not surprising because similar hysteresis has been reported for TCs adsorption on marine sediment and on acidic soils (Xu and Li, 2010; Fernandez-Calvino et al., 2015). It is believed that hysteresis is the result of partially irreversible sorption such as strong bonds established between antibiotic molecules and adsorbent surfaces. Braida et al. (2003) reported that hysteresis is due to irreversible pore deformation, which results in the pathway of sorption being different than that of desorption and which leads to entrapment of the sorbate as the polyaromatic scaffold collapses during desorption. The desorption hysteresis indicated that a portion of OTC will persist in marine sediment under the natural environment.

The data obtained from desorption process were found to be fitted the kinetic model very well as demonstrated by good regression coefficients $\left(R^{2}>0.990\right)$. From the goodness-of-fit 


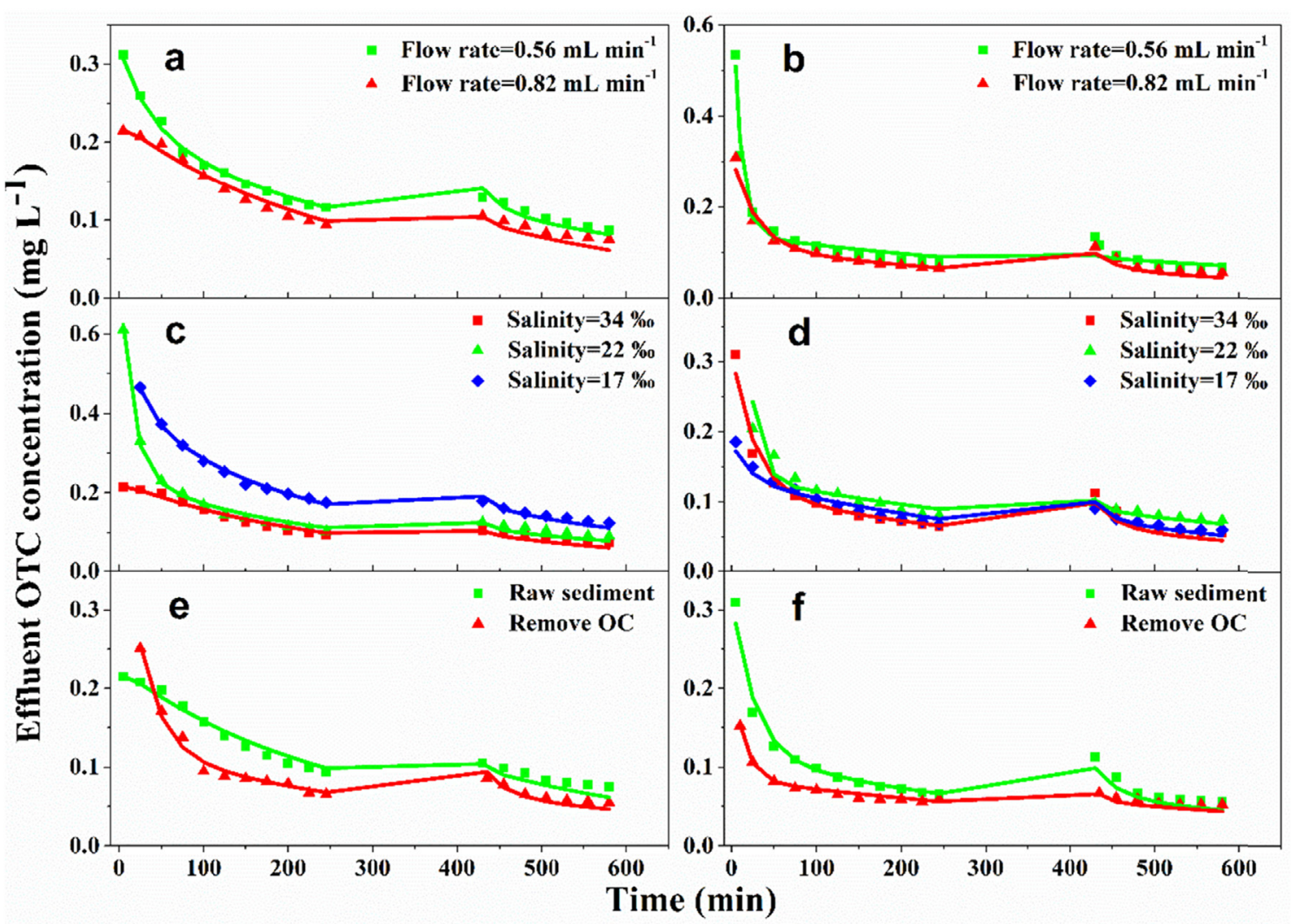

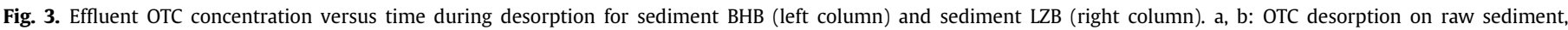

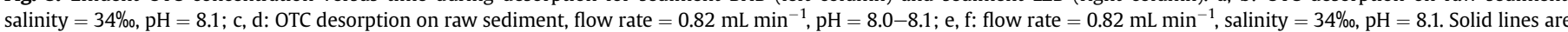
second order kinetic model simulations using parameters in Table 3.

results of Table 3, we can find that the kinetic rates of OTC adsorption vary in a narrow range, indicating the effects of salinity and $\mathrm{OC}$ on the kinetic rates are small. Nevertheless, a negative relation between the kinetic rates and salinity can be found (Table 3). For example, the $k_{d}$ values were $0.253,0.167$, and 0.119 $\min ^{-1}$ for salinity $34 \%, 22 \%$, and $17 \%$, respectively. In addition, desorption curves of OTC almost overlap at different flow rates, this may be due to OTC desorption from marine sediment was fast.

\subsection{Environmental implications}

Adsorption of OTC on sediment is complex considering that it can exist as different species at environmentally relevant $\mathrm{pH}$ values. Although many processes can influence the sorption of OTC, data of

Table 3

Optimized second order kinetic model parameter for desorption of OTC on marine sediments.

\begin{tabular}{|c|c|c|c|c|c|c|}
\hline \multirow[t]{2}{*}{ Sediment } & \multirow{2}{*}{$\frac{\text { Flow rate }}{\mathrm{mL} \mathrm{min}^{-1}}$} & \multirow{2}{*}{$\frac{\text { Salinity }}{\% 0}$} & \multirow{2}{*}{$\frac{\text { Remove OC }}{\mathrm{Y} / \mathrm{N}}$} & \multirow{2}{*}{$\frac{k_{d}}{\left(\min ^{-1}\right)}$} & \multirow[t]{2}{*}{$\mathrm{R}^{2}$} & \multirow[t]{2}{*}{ RMSE } \\
\hline & & & & & & \\
\hline \multirow[t]{5}{*}{ BHB } & 0.56 & 34 & $\mathrm{~N}$ & 0.109 & 0.999 & 0.00623 \\
\hline & 0.82 & 34 & $\mathrm{~N}$ & 0.207 & 0.996 & 0.00921 \\
\hline & 0.82 & 34 & Y & 0.103 & 0.996 & 0.00699 \\
\hline & 0.82 & 22 & $\mathrm{~N}$ & 0.148 & 0.998 & 0.0110 \\
\hline & 0.82 & 17 & $\mathrm{~N}$ & 0.134 & 0.999 & 0.00790 \\
\hline \multirow[t]{5}{*}{ LZB } & 0.56 & 34 & $\mathrm{~N}$ & 0.234 & 0.991 & 0.0177 \\
\hline & 0.82 & 34 & $\mathrm{~N}$ & 0.253 & 0.992 & 0.0134 \\
\hline & 0.82 & 34 & $\mathrm{Y}$ & 0.148 & 0.997 & 0.00472 \\
\hline & 0.82 & 22 & $\mathrm{~N}$ & 0.167 & 0.995 & 0.0155 \\
\hline & 0.82 & 17 & $\mathrm{~N}$ & 0.119 & 0.996 & 0.00671 \\
\hline
\end{tabular}

equilibrium batch experiments showed that OTC adsorption is under the impact of $\mathrm{pH}$, seawater salinity, and physicochemical properties of marine sediments. Our research findings are of significance to investigate the fate and transport of OTC in coastal water, where the $\mathrm{pH}$ and salinity usually vary in a wide range because of the inflow of freshwater. The optimized second order kinetic model parameter showed OTC adsorption was relatively slow. In addition, percentage of OTC desorption from marine sediment was large. These indicated that OTC and other similar antibiotics can exist in coastal water for a long time and will pose a great threat on aquatic organisms as well as human. The present study can be used as a reference to simulate transport of OTC in coastal water-sediment system.

\section{Conclusion}

Equilibrium and kinetic sorption of OTC on two marine sediments were determined using batch and SFC experiments to evaluate its mobility in marine environment. Adsorption of OTC was higher on sediment BHB than on sediment LZB because of its high OC, fine particles, and $\mathrm{Al}$ oxides content. The calculated Freundlich and Langmuir parameters showed significant differences under different salinity and $\mathrm{pH}$, indicating their large impact on the extent of OTC sorption on marine sediments. The results of equilibrium batch experiments demonstrated that combined adsorption mechanism such as hydrophobic interaction, ion exchange, H-bonding, and surface complexation might be involved in OTC adsorption processes. A second order kinetic model with optimized parameters successfully described the timedependent adsorption/desorption results from SFC equipment 
and reproduced the concentration change during stop-flow. Kinetic rate of adsorption showed small variation under different experimental conditions, which indicate the dominance of physical nonequilibrium, e.g., diffusive mass transfer from bulk solution to sorption sites inside sediments. After extensive leaching with background solution, $43-75 \%$ and $58-75 \%$ of sorbed OTC was released for sediment LZB and sediment BHB, respectively. Binding force of OTC on marine sediment was relatively weak as demonstrated by a relatively weak hysteresis. Our study indicated that time-dependent processes and environmental factors such as $\mathrm{pH}$ and salinity need to be included in water quality models to predict the fate and transport of OTC in coastal and estuarine waters.

\section{Acknowledgements}

This study was financially supported by National Nature Science Foundation of China (41271506, 41230858), Joint Project of the National Natural Science Foundation of China and Shandong Province (U1406403), and Key Research Program of the Chinese Academy of Sciences (KZZD-EW-14).

\section{Appendix A. Supplementary data}

Supplementary data related to this article can be found at http:// dx.doi.org/10.1016/j.chemosphere.2016.08.100.

\section{References}

Aristilde, L., Marichal, C., Miehe-Brendle, J., Lanson, B., Charlet, L., 2010. Interactions of oxytetracycline with a smectite clay: a spectroscopic study with molecular simulations. Environ. Sci. Technol. 44, 7839-7845.

Braida, W.J., Pignatello, J.J., Lu, Y.F., Ravikovitch, P.I., Neimark, A.V., Xing, B.S., 2003. Sorption hysteresis of benzene in charcoal particles. Environ. Sci. Technol. 37 409-417.

Brusseau, M.L., Jessup, R.E., Rao, P.S.C., 1991. Nonequilibrium sorption of organicchemicals- elucidation of rate-limiting processes. Environ. Sci. Technol. 25, $134-142$.

Brusseau, M.L., Rao, P.S.C., 1991. Influence of sorbate structure on nonequilibrium sorption of organic-compounds. Environ. Sci. Technol. 25, 1501-1506.

Carrasquillo, A.J., Bruland, G.L., Mackay, A.A., Vasudevan, D., 2008. Sorption of ciprofloxacin and oxytetracycline zwitterions to soils and soil minerals: influence of compound structure. Environ. Sci. Technol. 42, 7634-7642.

Chelossi, E., Vezzulli, L., Milano, A., Branzoni, M., Fabiano, M., Riccardi, G., Banat, I.M., 2003. Antibiotic resistance of benthic bacteria in fish-farm and control sediments of the Western Mediterranean. Aquaculture 219, 83-97.

Cornelissen, G., Breedveld, G.D., Kalaitzidis, S., Christanis, K., Kibsgaard, A., Oen, A.M.P., 2006. Strong sorption of native PAHs to pyrogenic and unburned carbonaceous geosorbents in sediments. Environ. Sci. Technol. 40, 1197-1203.

Drillia, P., Stamatelatou, K., Lyberatos, G., 2005. Fate and mobility of pharmaceuticals in solid matrices. Chemosphere 60, 1034-1044.

Fernandez-Calvino, D., Bermudez-Couso, A., Arias-Estevez, M., Novoa-Munoz, J.C., Fernandez-Sanjurjo, M.J., Alvarez-Rodriguez, E., Nunez-Delgado, A., 2015. Kinetics of tetracycline, oxytetracycline, and chlortetracycline adsorption and desorption on two acid soils. Environ. Sci. Pollut. Res. 22, 425-433.

Ferro-Garcia, M.A., Rivera-Utrilla, J., Bautista-Toledo, I., Moreno-Castilla, C., 1998 Adsorption of humic substances on activated carbon from aqueous solutions and their effect on the removal of $\mathrm{Cr}(\mathrm{III})$ ions. Langmuir 14, 1880-1886.

Hendershot, W.H., Singleton, G.A., Lavkulich, L.M., 1979. Variation in surface-change characteristics in a soil chronosequence. Soil. Sci. Soc. Am. J. 43, 387-389.
Heuer, O.E., Kruse, H., Grave, K., Collignon, P., Karunasagar, I., Angulo, F.J., 2009. Human health consequences of use of antimicrobial agents in aquaculture. Clin. Infect. Dis. 49, 1248-1253.

Huang, W.L., Young, T.M., Schlautman, M.A., Yu, H., Weber, W.J., 1997. A distributed reactivity model for sorption by soils and sediments .9. General isotherm nonlinearity and applicability of the dual reactive domain model. Environ. Sci. Technol. 31, 1703-1710.

Jjemba, P.K., 2002. The potential impact of veterinary and human therapeutic agents in manure and biosolids on plants grown on arable land: a review. Agr. Ecosyst. Environ. 93, 267-278.

Jones, A.D., Bruland, G.L., Agrawal, S.G., Vasudevan, D., 2005. Factors influencing the sorption of oxytetracycline to soils. Environ. Toxicol. Chem. 24, 761-770.

Jones, O.A.H., Voulvoulis, N., Lester, J.N., 2002. Aquatic environmental assessment of the top 25 English prescription pharmaceuticals. Water Res. 36, 5013-5022.

Le, T.X., Munekage, Y., 2004. Residues of selected antibiotics in water and mud from shrimp ponds in mangrove areas in Viet Nam. Mar. Pollut. Bull. 49, 922-929.

Liu, Y.X., Bao, Y.Y., 2011. A review on pollution situation of tetracycline antibiotics in soil environment. Environ. Pollut. Control 33, 81-86.

Ma, L.W., Selim, H.M., 1994. Predicting atrazine adsorption-desorption in soils: a modified second-order kinetic model. Water Resour. Res. 30, 447-456.

Maszkowska, J., Kolodziejska, M., Bialk-Bielinska, A., Mrozik, W., Kumirska, J., Stepnowski, P., Palavinskas, R., Krueger, O., Kalbe, U., 2013. Column and batch tests of sulfonamide leaching from different types of soil. J. Hazard. Mater. 260, 468-474.

Miller, C.T., Weber, W.J., 1988. Modeling the sorption of hydrophobic contaminants by aquifer materials-II. Column reactor systems. J. Water Res. 22, 465-474.

Nonaka, L., Ikeno, K., Suzuki, S., 2007. Distribution of tetracycline resistance gene, tet(M), in Gram-positive and Gram-negative bacteria isolated from sediment and seawater at a coastal aquaculture site in Japan. Microbes Environ. 22, 355-364.

Press, W.H., Teukolsky, S.A., Vetterling, W.T., Flannery, B.P., 1992. Numerical Recipes in FORTRAN, second ed. Cambridge Univ. Press, New York.

Rabolle, M., Spliid, N.H., 2000. Sorption and mobility of metronidazole, olaquindox, oxytetracycline and tylosin in soil. Chemosphere 40, 715-722.

Sassman, S.A., Lee, L.S., 2005. Sorption of three tetracyclines by several soils: assessing the role of $\mathrm{pH}$ and cation exchange. Environ. Sci. Technol. 39, $7452-7459$

Song, X., Liu, D., Zhang, G., Frigon, M., Meng, X., Li, K., 2014. Adsorption mechanisms and the effect of oxytetracycline on activated sludge. Bioresour. Technol. 151, $428-431$.

Tamminen, M., Karkman, A., Lohmus, A., Muziasari, W.I., Takasu, H., Wada, S., Suzuki, S., Virta, M., 2011. Tetracycline resistance genes persist at aquaculture farms in the absence of selection pressure. Environ. Sci. Technol. 45, 386-391.

ter Laak, T.L., Gebbink, W.A., Tolls, J., 2006. The effect of $\mathrm{pH}$ and ionic strength on the sorption of sulfachloropyridazine, tylosin, and oxytetracycline to soil. Environ. Toxicol. Chem. 25, 904-911.

Thiele-Bruhn, S., 2003. Pharmaceutical antibiotic compounds in soils-a review. J. Plant Nutr. Soil S. C. 166, 145-167.

Turku, I., Sainio, T., Paatero, E., 2007. Thermodynamics of tetracycline adsorption on silica. Environ. Chem. Lett. 5, 225-228.

Wang, J.T., Hu, J., Zhang, S.W., 2010. Studies on the sorption of tetracycline onto clays and marine sediment from seawater. J. Colloid Interface Sci. 349, 578-582.

Wershaw, R.L., 1986. A new model for humic materials and their interactions with hydrophobic organic chemicals in soil-water or sediment-water systems. J. Contam. Hydrol. 1, 29-45.

Xu, X.R., Li, X.Y., 2010. Sorption and desorption of antibiotic tetracycline on marine sediments. Chemosphere 78, 430-436.

Yang, W., Zheng, F., Lu, Y., Xue, X., Li, N., 2011. Adsorption interaction of tetracyclines with porous synthetic resins. Ind. Eng. Chem. Res. 50, 13892-13898.

Zhang, H., Selim, H.M., 2011. Second-order modeling of arsenite transport in soils. J. Contam. Hydrol. 126, 121-129.

Zhang, X.X., Zhang, T., 2011. Occurrence, abundance, and diversity of tetracycline resistance genes in 15 sewage treatment plants across China and other global locations. Environ. Sci. Technol. 45, 2598-2604.

Zhang, Y.B., Li, Y., Sun, X.L., 2011. Antibiotic resistance of bacteria isolated from shrimp hatcheries and cultural ponds on Donghai Island, China. Mar. Pollut. Bull. 62, 2299-2307. 